LETTERS

\section{Neonatal randomised point- of-care trials are feasible and acceptable in the UK: results from two national surveys}

Randomised point-of-care trials (POCT) ${ }^{1}$ or registry trials $^{2}$ offer a potentially efficient, convenient and cost-effective alternative to conventional randomised controlled trials. By using information present in an existing database, registry or electronic patient record (EPR), POCT eliminate the need for duplicative data collection. ${ }^{1}$ Neonatal medicine is well placed to use this methodology; an existing national resource, the National Neonatal Research Database (NNRD), holds detailed data extracted from the neonatal EPR of all National Health Service neonatal units in England, Wales and Scotland; contributing units are known as the UK Neonatal Collaborative (UKNC).

We assessed the acceptability of neonatal POCT using the NNRD in two surveys. In the first (March-June 2014), we emailed all English UKNC leads, proposed a neonatal POCT and asked whether their unit would be willing to participate. In the second, we examined attitudes towards the neonatal EPR. We emailed neonatal trainees $(n=108)$ and lead nurses, and asked them to cascade the survey on their unit. Using validated ${ }^{3}$ questions, we asked respondents about their current satisfaction with the EPR;
POCT methodology was then described, and respondents rated their predicted satisfaction with using EPR data in this way using a Likert scale.

A total of 111/163 (68\%) UKNC neonatal unit contacts responded to the first survey; 97/111 (87\%) respondents expressed willingness for their neonatal unit to take part in the proposed POCT. A total of 162 neonatal health professionals responded to the second survey. Respondents were generally satisfied with the neonatal EPR (table 1). Approximately one in three indicated that using EPR data for POCT would lead them to view it as more worthwhile (table 2). A total of 139/ $157(88 \%)$ respondents agreed with the statement, 'if parents' consent, I support using the EPR system to gather data for randomised trials'. The theme that emerged from narrative responses concerned EPR data quality.

We show that neonatal practitioners in England are willing to participate in POCT using EPR. Using neonatal data in this way is acceptable, and associated with greater satisfaction with the EPR in approximately one-third of the respondents. There is currently a high level of satisfaction with the UK neonatal EPR. Those surveyed have identified the need to improve EPR data quality; the neonatal EPR is used clinically and to generate discharge summaries, so enhancing data quality could also benefit patient care. Strengths include the national distribution and high response rates, although the voluntary nature may mean individuals with enthusiasm for the EPR are over-represented.

Table 1 Current satisfaction with the neonatal electronic patient record (EPR)

\begin{tabular}{llll}
\hline & Agreement, all & $\begin{array}{l}\text { Agreement, } \\
\text { doctors }\end{array}$ & $\begin{array}{l}\text { Agreement, } \\
\text { nurses }\end{array}$ \\
\hline I feel that the EPR is useful & $148 / 162(91 \%)$ & $38 / 40(95 \%)$ & $95 / 106(90 \%)$ \\
The EPR is worth the time and effort required to use it & $134 / 162(83 \%)$ & $30 / 40(75 \%)$ & $91 / 106(86 \%)$ \\
Overall, I am satisfied with the electronic patient record & $126 / 162(79 \%)$ & $28 / 40(70 \%)$ & $86 / 106(82 \%)$ \\
\hline Data are presented as n/N (\%) & & & \\
\hline
\end{tabular}

Neonatal practice is insufficiently evidence-based; $58 \%$ of neonatal Cochrane reviews published between 2006 and 2010 were inconclusive. ${ }^{4}$ Using existing EPR for randomised POCT would represent an important innovation, potentially improving neonatal care rapidly, and at lower cost than is presently the case. The results of our study are encouraging, and suggest that this approach would be well received, and increase the perceived utility of the EPR. We are currently undertaking work to understand parent views and determine research types suitable for this methodology. In conclusion, POCT using EPR and the NNRD are feasible and acceptable to health professionals.

Christopher Gale, Neena Modi, on behalf of the WHEAT trial development group

Section of Neonatal Medicine, Department of Medicine, Imperial College London, Chelsea and Westminster Hospital campus, London, UK

Correspondence to Professor Neena Modi, Section of Neonatal Medicine, Department of Medicine, Imperial College London, Chelsea and Westminster Hospital campus, 369 Fulham Road, London SW10 9NH, UK; n.modi@imperial.ac.uk

Collaborators WHEAT trial development group members: C Gale, NIHR clinical lecturer, Imperial College London; N Modi, Professor of Neonatal Medicine, Imperial College London; H Robberts, mother of preterm twins; Z Chivers, Head of Services, Bliss; A Forster, neonatal nurse, James Cook Hospital, Middlesbrough; M Turner, Senior Lecturer in Neonatal Medicine, University of Liverpool; J Dorling, Clinical Associate Professor of Neonatal Medicine, University of Nottingham; TP van Staa, Professor of eHealth Research, University of Manchester and Utrecht Institute for Pharmaceutical Sciences, Utrecht University.

Contributors CG and NM conceived the study; CG designed the survey and collected study data; CG, NM and all members of the WHEAT trial development group contributed to writing the paper.

Funding This study was funded by an Academy of Medical Sciences Starter Grant for Clinical Lecturers, supported by the Medical Research Council, Wellcome Trust, British Heart Foundation, Arthritis Research UK, Prostate Cancer UK and The Royal College of Physicians.

\section{Competing interests None declared.}

Provenance and peer review Not commissioned; internally peer reviewed.

Data sharing statement Unpublished data are available on request from the corresponding author.

Table 2 How respondent's perceptions would change if electronic patient record (EPR) data were used for point-of-care trials

\begin{tabular}{|c|c|c|c|c|c|c|}
\hline & $\begin{array}{l}\text { Stronger } \\
\text { agreement, all }\end{array}$ & $\begin{array}{l}\text { Less } \\
\text { agreement, all }\end{array}$ & $\begin{array}{l}\text { Stronger } \\
\text { agreement, } \\
\text { doctors }\end{array}$ & $\begin{array}{l}\text { Less } \\
\text { agreement, } \\
\text { doctors }\end{array}$ & $\begin{array}{l}\text { Stronger } \\
\text { agreement, } \\
\text { nurses }\end{array}$ & $\begin{array}{l}\text { Less } \\
\text { agreement, } \\
\text { nurses }\end{array}$ \\
\hline The EPR is useful & $50 / 162(32 \%)$ & $4 / 162(3 \%)$ & $18 / 40(46 \%)$ & $4 / 40(10 \%)$ & $27 / 106(26 \%)$ & $0 / 106(0 \%)$ \\
\hline The EPR is worth the time and effort required to use it & $55 / 162(35 \%)$ & $3 / 162(2 \%)$ & $19 / 40(50 \%)$ & $3 / 40(7 \%)$ & $33 / 106(32 \%)$ & $0 / 106(0 \%)$ \\
\hline Overall, I am satisfied with the electronic patient record & $42 / 162(27 \%)$ & $5 / 162(3 \%)$ & $16 / 40(43 \%)$ & $5 / 40(13 \%)$ & $22 / 106(21 \%)$ & $0 / 106(0 \%)$ \\
\hline
\end{tabular}




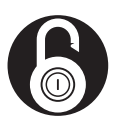

OPEN ACCESS
4 Willhelm C, Girisch W, Gottschling S, et al. Systematic Cochrane reviews in neonatology: a critical appraisal. Pediatr Neonatol 2013;54:261-6.

Open Access This is an Open Access article distributed in accordance with the terms of the Creative Commons Attribution (CC BY 4.0) license, which permits others to distribute, remix, adapt and build upon this work, for commercial use, provided the original work is properly cited. See: http:// creativecommons.org/licenses/by/4.0/

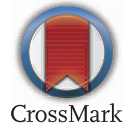

To cite Gale C, Modi N, on behalf of the WHEAT trial development group. Arch Dis Child Fetal Neonatal Ed 2016;101:F86-F87.

Accepted 8 June 2015

Published Online First 23 October 2015

Arch Dis Child Fetal Neonatal Ed 2016;101:F86-F87. doi:10.1136/archdischild-2015-308882

\section{REFERENCES}

1 van Staa TP, Dyson L, McCann G, et al. The opportunities and challenges of pragmatic point-of-care randomised trials using routinely collected electronic records: evaluations of two exemplar trials. Health Technol Assess 2014;18:1-146.

2 Lauer MS, D'Agostino RB Sr. The randomized registry trial-the next disruptive technology in clinical research? N Engl J Med 2013;369:1579-81.

3 Secginli S, Erdogan S, Monsen KA. Attitudes of health professionals towards electronic health records in primary health care settings: a questionnaire survey. Inform Health Soc Care 2014; 39:15-32. 